\title{
TUTELAS PROVISÓRIAS E O NOVO CPC
}

PROVISIONAL TUTORS AND THE NEW CPC

Luísa Barbosa Pessoa'

ISSUE DOI: $10.21207 / 1983.4225 .375$

\section{RESUMO}

Ao ser sancionado um Novo Código de Processo Civil, muitas mudanças foram percebidas, e dentre as mais impactantes está a Tutela Provisória, que veio atualizar, modificar e orientar de uma maneira sistematicamente organizada o ordenamento jurídico no que diz respeito à antecipação da tutela ou tutela cautelar. Este trabalho apresenta as principais mudanças trazidas pelo Novo CPC em face do Código vigente anterior no que se pode tratar dentro do assunto de Tutela Provisória, tendo em vista a grande necessidade de ser estudada, entendida e aplicada de maneira competente e juridicamente eficaz, pois o principal adversário processual de quem encontra-se em uma situação de urgência ou emergência é o tempo, e a demanda principal do litigante passa a ser a busca pela celeridade em sua causa. O Código de Processo Civil de 2015 dispôs a temática em seu Livro V, o qual ganhou título de "Da Tutela Provisória", e unificou tudo que estava esparsamente ordenado pelo $\mathrm{CPC} / 73$, de maneira topograficamente mais clara e até mais concisa, proporcionando ao julgador experimentar maior amplitude de valoração casuística. Os objetivos que se fizeram para esta pesquisa, além de apresentarem as mudanças proporcionadas pelo novo Diploma legal, pautaram-se em estudar a função constitucional e a história da Tutela Provisória e como foi o seu surgimento e desenvolvimento no ordenamento jurídico ao longo do tempo, de acordo

\footnotetext{
${ }^{1}$ Graduanda em Direito pela Faculdade de Direito de Franca.
} 
com as necessidades sociais que fizeram com que surgisse, ou seja, a impossibilidade de se esperar o fim do processo de conhecimento face à urgência ou emergência. Para apresentar as principais mudanças, fez-se necessário o estudo de como era disciplinada a Tutela Provisória no Código de Processo Civil de 1973, tecer os conceitos, aplicações práticas dos institutos cautelares e antecipatórios e esclarecer as espécies de Tutela Provisória dentro do Novo CPC, sendo: de Urgência e de Evidência, de acordo com seus pressupostos. A produção de uma pesquisa científica em torno do referido assunto proporcionou a conclusão de que o novo ordenamento processual civil trouxe uma superação na prestação jurisdicional, pois permite ao juízo oferecer uma tutela diferenciada, apresentados os requisitos de perigo de dano irreparável ou de difícil reparação, a probabilidade do direito ou ainda o manifesto propósito protelatório do réu, sem que tal decisão aconteça em detrimento do mérito do processo, permitindo ao litigante de boa-fé receber a justiça que buscava.

Palavras Chave: Novo CPC. Tutela Provisória. Urgência. Emergência. Celeridade Processual.

\section{ABSTRACT}

When a new Code of Civil Procedure was sanctioned, many times they were damaged, and are the most striking of a Provisional Guardianship, which came to update, modify and guide in an organized organized way the legal system, which does not concern the anticipation of Guardianship or guardianship. This work has as main changes brought by the New CPC in the face of the previous Code that can not be dealt with within the text of Provisional Tutorship, in view of a great need to study, understood and applied in a competent and juridical way the Process Code The Civil Code of 2015 has a theme in its Book V, which won the title of "Provisional Guardianship", and that all items were ordered by CPC / 73, in a clearer and faster way, giving the Judge a greater breadth of Case-by-case evaluation. The objectives of this research, besides presenting as changes provided by the new Legal Diploma, were based on studying a constitutional function and history of the Provisional Tutorship and how it was for its development and development in the legal-temporal order throughout the Time, According to the social needs that result with the discovery, ie the impossibility of waiting for the end of the process of knowledge the ur- 
gency or urgency. To become like the changes of principle, it became necessary to study how to discipline a Provisional Guardianship in the Code of Civil Procedure of 1973, to weave concepts, practical applications of the precautionary and anticipatory institutes and to clarify how species of Provisional Guardianship within Of the New CPC, being: Urgency and Evidence, according to their assumptions. The production of a scientific research around the drawing according to the conclusion that the new procedural order of construction of a solution of overcoming in the provision of jurisdiction, Irreparable or difficult to repair, a probability of right or even a manifest purpose To the detriment of the merits of the proceedings, allowing the litigant in good faith to receive a justice that he sought.

Keywords: New code of civil procedure. Provisional guardianship. Urgency. Emergency. Process acceleration.

\section{INTRODUÇÃO}

A pesquisa apresentada teve a escolha do seu tema pautado nas modificações processuais que o Novo Código de Processo Civil trouxe ao ordenamento jurídico brasileiro no que diz respeito à Tutela Provisória, pois verificou-se uma grande quantidade de inovações que reestruturaram a disposição até então existente, e a reforma procedimental a que os personagens do processo terão de enfrentar para tornarem-se adequados.

O processo pode tornar-se mecanismo de prejuízo para o litigante, pois exige muito tempo para que se cumpra, e aquele está diante de uma situação imediata e emergente, não se pode colocar a correr os riscos de sofrer um dano irreparável ou de difícil reparação, ou mesmo suportar o ônus temporal diante de uma defesa do réu meramente protelatória ou sem fundamento.

Com o escopo de encerrar o dissabor causado pela longa espera processual, é que se fez com que fossem trabalhadas as concepções de tutelas distintas das obtidas no processo de conhecimento sob óticas diferentes, criando-se então o instituto da antecipação da tutela e da tutela cautelar, fazendo com que medidas provisórias e imediatas pudessem ser tomadas diante de ocasiões em que a longa demanda de tempo não é bemvinda. 


\section{HISTÓRIA DAS TUTELAS PROVISÓRIAS E SUA FUNÇÃO CONSTITUCIONAL}

O Código de Processo Civil de 1973 originalmente não trazia nenhuma possibilidade de ocorrerem decisões judiciais que antecipassem a tutela, permitindo que muitos casos ficassem suscetíveis de sofrer algum prejuízo, em decorrência do periculum in mora, ou seja a demora da prestação jurisdicional e a ausência do fumus boni iuris.

A ausência desse instituto no Código de Processo Civil de 1973 até então deixava a desejar questões de urgência e evidência, isto é, era um Diploma omisso com relação a um assunto tão importante, causando danos em situações nas quais o juízo não possuía poder para remediar o lastro de tempo demandado. Causava prejuízos em função da não satisfação de um direito pleiteado pelo autor no processo de conhecimento, cuja decisão de mérito ao ser pronunciada, já não produzia efeitos, tornando-se praticamente inútil, pois o que poderia ter sido tutelado em tempo, faziase ausente, então o objeto do processo já encontrava-se perecido.

Ao verificar a importância e iminente necessidade de tipificar no Código de Processo Civil um instituto que traria a antecipação da tutela, sem prejudicar o mérito do processo, sancionou-se a Lei $\mathrm{n}^{\circ} 8.952$, de 13 de dezembro de 1994, que vislumbrava a possibilidade de o magistrado encerrar suas decisões caso a caso, remediando os efeitos do tempo quando necessário.

Código de Processo Civil de 1973. (Redação dada pela Lei $\mathrm{n}^{\circ}$ 8.952, de 13.12.1994):

Art. 273. O juiz poderá, a requerimento da parte, antecipar, total ou parcialmente, os efeitos da tutela pretendida no pedido inicial, desde que, existindo prova inequívoca, se convença da verossimilhança da alegação e:

I - haja fundado receio de dano irreparável ou de difícil reparação; ou

II - fique caracterizado o abuso de direito de defesa ou o manifesto propósito protelatório do réu.

$\S 1^{\circ} \mathrm{Na}$ decisão que antecipar a tutela, o juiz indicará, de modo claro e preciso, as razões do seu convencimento. 
$\S 2^{\circ}$ Não se concederá a antecipação da tutela quando houver perigo de irreversibilidade do provimento antecipado.

$\S 3^{\circ} \mathrm{A}$ execução da tutela antecipada observará, no que couber, o disposto nos incisos II e III do art. 588.

$\S 4^{\circ}$ A tutela antecipada poderá ser revogada ou modificada a qualquer tempo, em decisão fundamentada.

$\S 5^{\circ}$ Concedida ou não a antecipação da tutela, prosseguirá o processo até final julgamento.

O sistema jurídico então passou a conviver com duas disciplinas: as tutelas antecipadas, cujos requisitos eram o fumus boni juris e o periculum in mora, e as tutelas cautelares, cuja aplicação era baseada na verossimilhança da alegação e no fundado receio de dano ou abuso do direito de defesa.

A Constituição da República Federativa Brasileira em seu artigo $5^{\circ}, \mathrm{XXXV}$ estabelece que "a lei não excluirá da apreciação do Poder Judiciário lesão ou ameaça a direito", tornando-se então a antecipação da tutela reconhecida como um direito fundamental, ou seja, trata-se de uma adequação da legislação aos parâmetros exigidos pelas necessidades sociais, para observar a tutela jurisdicional de maneira correta.

$\mathrm{O}$ art. 273 do CPC/73 foi primordial para trazer ao magistrado a possibilidade de antecipar a tutela, total ou parcialmente conforme a conveniência do caso. Luiz Guilherme Marinoni2 acrescenta que: "O art.273, $\mathrm{CPC}$, é uma resposta do legislador infraconstitucional ao seu imperativo de organizar um processo civil capaz de outorgar tutela jurisdicional adequada e efetiva aos direitos".

O Código de Processo Civil foi pontualmente acrescentado e reformado várias vezes nos vários campos de abrangência de que trata o Processo Civil. E por conta disso chegou-se a um consenso jurídico quanto à aplicação da norma, no sentido de que o Código de Processo Civil de 1973, como um todo, passou a sofrer uma considerável acentuação do número das modificações sofridas, que ocorriam através da criação de alguns institutos e da reestruturação de outros, e um claro exemplo disso

\footnotetext{
${ }^{2}$ MARINONI, Luiz Guilherme. MITIDIERO, Daniel. Código de Processo Civil Comentado Artigo por Artigo. 5a Edição revista e atualizada. 2013. p. 266.
} 
é o próprio assunto em pauta, a tutela provisória. Por isso, decidiu-se que o CPC/73 precisaria ser substituído, afinal passou a não mais atender às necessidades jurisdicionais e também a não conceder ao processo uma celeridade plausível.

\section{TUTELAS PROVISÓRIAS NO CÓDIGO DE PROCESSO CIVIL DE 1973}

Elucidar e entender a disposição do Código de Processo Civil de 1973 através de uma explanação geral é de suma importância para que se possa posteriormente entender as propostas do Novo Diploma Processual Civil, dessa forma, serão abrangidos os principais aspectos de como as tutelas provisórias eram disciplinadas.

O Código de Processo Civil de 1973 trazia quatro espécies de Tutela Provisória: as Tutelas Cautelares, as Tutelas Antecipadas, as Tutelas de Evidência e as Tutelas Satisfativas Autônomas.

As tutelas cautelares asseguram uma tutela do direito ou um fato jurídico tutelável e deve fazer parte de outro processo que já esteja em andamento, tendo como finalidade protetiva e assecuratória de um direito, o qual não se antecipa o resultado, mas sim, protege-o. Não se trata de um instrumento de outro processo, caracterizado como principal, e sim de um instrumento capaz de assegurar a tutela do direito material ou de uma disposição jurídica tutelável, que de modo geral consiste objeto de um processo distinto. Porém, tal fato não exclui a tutela cautelar do aspecto da instrumentalidade, podendo esta ser requerida frente a uma situação futura (prejuízo eventual) ou já ocorrida.

As tutelas antecipadas são disciplinadas pelo inciso I do artigo 273 do Código de Processo Civil de 1973, "I. haja fundado receio de dano irreparável ou de difícil reparação", e ao ser concedida, a tutela final pleiteada é adiantada pelo juízo para antes do momento que naturalmente é reservado para o julgamento do mérito, porque o que se espera ao conceder tal antecipação é poupar possível dano ao direito subjetivo da parte, por isso é baseada na urgência.

As Tutelas baseadas na evidência são ordenadas pelo inciso II do artigo 273 do Código de Processo Civil de 1973, "II. fique caracterizado o abuso de direito de defesa ou o manifesto propósito protelatório do réu.". O que se busca combater é o tempo, pois sabe-se que este é inimigo 
do processo e consequentemente da proteção dos direitos subjetivos, tornando-se um fardo. Ao introduzir no artigo 273 o segundo inciso, o legislador efetivou a proteção do autor diante do benefício que o réu poderia obter em favor do tempo que o processo leva até a decisão de mérito, o que caracterizaria uma injustiça, haja vista que a distribuição do tempo para autor e réu deve ser par, de modo a não trazer prejuízo àquele que busca uma solução diante da sua razão, o autor.

Quando se trata de tutela de evidência, não há que se falar em dano, pois trata-se do indício da existência do direito material. Para isso, a justiça irá sopesar as alegações, pois, de qualquer modo, o réu não poderá em hipótese alguma perder o seu direito ao contraditório e à ampla defesa, e então se o autor fizer uma argumentação mais robusta e comprobatória da sua prerrogativa sobre o que pleiteia, será concedida a medida liminar, tutela com sustentação na veracidade de sua alegação.

As Tutelas Satisfativas Autônomas não possuem provisórios os seus efeitos, posto que as repercussões são irreversíveis. Porém, conforme texto do artigo 807 pode haver a revogabilidade da decisão; e de acordo com o artigo 810, essa espécie de tutela não faz coisa julgada. Código de Processo Civil de 1973, respectivamente:

Art. 807. as medidas cautelares conservam a sua eficácia no prazo do artigo antecedente e na pendência do processo principal; mas podem, a qualquer tempo, ser revogadas ou modificadas.

Parágrafo único. salvo decisão judicial em contrário, a medida cautelar conservará a eficácia durante o período de suspensão do processo.

Art. 810. O indeferimento da medida não obsta a que a parte intente a ação, nem influi no julgamento desta, salvo se o juiz, no procedimento cautelar, acolher a alegação de decadência ou de prescrição do direito do autor.

Para aclarar a aplicabilidade do assunto em pauta, seguem alguns exemplos: quando uma pessoa necessita de um ou mais remédios de alto custo, cuja ausência poderia afetar irreparavelmente sua saúde, ou até levá-lo a morte; em um processo de execução, aquele réu que possui o intento de frustrar a ação, esgota seu patrimônio para impossibilitar que perca seus bens, afinal, se "nada possui", não tem o que ser executado. 
Sabendo o credor disto, deve ajuizar uma medida cautelar a fim de que ainda receba o seu crédito; ou então, um plano de saúde que se nega a realizar um procedimento cirúrgico urgente por alegar que o plano não cobre mais tal método operatório, sendo que anteriormente o fazia.

Nesses casos, é necessária a imediata antecipação dos efeitos da tutela pretendida, não permitindo que ação movida torne-se inútil em função da urgência indispensável da sentença final, dando a possibilidade de se alcançar o objetivo de uma justiça efetiva.

De acordo com o direito europeu contemporâneo, a antecipação da tutela foi subdividia em medidas provisórias de natureza cautelar (instrumento de ação cautelar) e medidas provisórias de natureza antecipatória (objeto de liminar na ação principal, facilitadas pela alteração do artigo 273, com a introdução da tutela em caráter genérico). Humberto Theodoro Júnior ${ }^{3}$ diz que "na atual sistemática do art. 273 do CPC, em qualquer fase do processo, é cabível a providência provisória de urgência.".

Tanto a tutela cautelar como a antecipatória possuem a preocupação de dizimar o problema do perigo de dano, porém, na prática encontram-se "muitas situações fronteiriças, que colocarão partes e juízes em sérias dificuldades para classificar a medida num ou noutro dos segmentos da tutela de prevenção.", expõe Humberto Theodoro Júnior ${ }^{4}$.

O fato de possuírem uma área de aplicação conceitual de diferenciação muito tênue, tornou-se difícil realizar a distinção sobre o que se deve pedir, o que acarretou em um excesso de tecnicismo por parte dos tribunais, permitindo negarem a tutela emergencial em um momento crucial para o demandante.

Ora, se a missão do aplicador do direito é impedir que haja dano grave e de difícil reparação, por que indeferir uma providência que postule tutela antecipatória, quando o que se almeja é obter uma medida cautelar, por exemplo, estando o magistrado diante de uma evidente emergência? Onde encontramos justiça quando a norma se torna tão máxima, incapaz de abstrair o caso concreto, não trazendo ao solicitante a devida prestação jurisdicional?

\footnotetext{
3 THEODORO JÚNIOR, Humberto. Curso de Direito Processual Civil: Teoria geral do direito processual civil e processo de conhecimento - Vol. I. 55 ${ }^{\text {a }}$ Edição. Rio de Janeiro: Forense. 2014. p. 412.

${ }^{4}$ Ibidem. p. 414.
} 
A reforma legislativa trazida pelo advento da Lei $\mathrm{n}^{\circ} 10.444$, de 07.05.2002, agregou os parágrafos $6^{\circ}$ e $7^{\circ}$ ao artigo 273 , e veio justamente para solucionar esse impasse legislativo, entre excesso de conceito e a necessidade na prática, pois permitiu ao aplicador da lei que realizasse a fungibilidade, o que significava que não seria indeferida a demanda caso fosse requerida uma tutela no lugar de outra, pois a redação dos parágrafos acrescentados permitia que o órgão julgador conhecesse e deferisse uma medida em lugar de outra, desde que presentes os pressupostos legais indispensáveis e necessários para isso, se conveniente e cabível fosse.

Código de Processo Civil de 1973. (Redação dada pela Lei $n^{\circ}$ 10.444 de 7 de maio de 2002):

$\S 6^{\circ}$ a tutela antecipada também poderá ser concedida quando um ou mais dos pedidos cumulados, ou parcela deles, mostrar-se incontroverso.

$\S 7^{\circ}$ se o autor, a título de antecipação de tutela, requerer providência de natureza cautelar, poderá o juiz, quando presentes os respectivos pressupostos, deferir a medida cautelar em caráter incidental do processo ajuizado.

No Código de Processo Civil de 1973, os requisitos a serem preenchidos para que se pudesse solicitar uma tutela antecipada ou cautelar eram: requerimento da parte, produção de prova inequívoca, convencimento do juiz quanto à verossimilhança da alegação, fundado receio de dano irreparável ou de difícil reparação, caracterização de abuso de direito de defesa ou manifesto propósito protelatório do réu e ainda possibilidade de reverter a medida antecipada

\section{TUTELAS PROVISÓRIAS NO CÓDIGO DE PROCESSO CIVIL DE 2015}

A tutela provisória ganhou no Código de Processo Civil de 2015 um livro exclusivo, o Livro V, que vem dispor de maneira equili- 
brada com a ordem jurídica, dos artigos 294 a 311, a nova sistematização trazida pelo legislador.

O Novo Código de Processo Civil, ao disciplinar a antecipação da tutela jurisdicional nas suas diversas modalidades e aspectos sob o título de "DA TUTELA PROVISÓRIA", trouxe consigo a unificação, e consequentes regras comuns dessas medidas, para que se pudesse simplificar o entendimento e aumentar seu campo de aplicação.

Quanto ao momento de propositura da ação, não há mais a limitação estabelecida pelo $\mathrm{CPC} / 73$, pois o artigo 294, parágrafo único do Novo CPC, diz que "A tutela provisória de urgência, cautelar ou antecipada, pode ser concedida em caráter antecedente ou incidental.".

Outra característica comum que a tutela provisória carrega consigo é o caráter de temporariedade e provisoriedade, sobre os quais Humberto Theodoro Júnior5 afirma que "conservam sua eficácia na pendência do processo, inclusive durante o período de suspensão", fundamentando ainda tal posicionamento no artigo 296 do Novo CPC.

A próxima regra inerente às tutelas provisórias diz respeito ao poder tutelar geral do juiz. O CPC/73 tratava deste instituto como sendo o "poder geral de cautela", no qual o juiz podia conceder, além das medidas cautelares nominadas, tutelas atípicas, ou seja, que não estavam sob a luz da legislação, em função da distância existente entre a situação concreta e o que a tipicidade protegia.

O Novo Código de Processo Civil veio tratar do assunto de maneira mais ampla, cujo título já é capaz de trazer a percepção de maior abrangência: "poder tutelar geral do juiz", pois de acordo com Humberto Theodoro Júnior6, este pressuposto abrange todas as medidas provisórias, sejam elas fundadas na urgência ou na evidência, não se restringindo apenas à hipóteses predefinidas por lei, pois há um entendimento nos estudos jurídicos de que o legislador, ao realizar a previsão legal nos códigos que regem a vida em sociedade, não conseguem antever e futurar todas as possibilidades fáticas e jurídicas das relações humanas, de modo

\footnotetext{
5 THEODORO JÚNIOR, Humberto. Curso de Direito Processual Civil: Teoria geral do direito processual civil, processo de conhecimento e procedimento comum - Vol. I. 56 Edição rev. atual. e ampl. Rio de Janeiro: Forense. 2015. p. 605.

${ }^{6}$ DIDIER JÚNIOR, Fredie; OLIVEIRA, Rafael Alexandria; BRAGA, Paula Sarno. Curso de Direito Processual Civil: teoria da prova, direito probatório, ações probatórias, decisão, precedente, coisa julgada e antecipação dos efeitos da tutela. 10 $0^{\mathrm{a}}$ Edição. Vol 2. Salvador: Ed. Jus Podivm. 2015. p. 603.
} 
que essa lacuna fica para valoração do juiz, e este ao fazer seu juízo de valor sobre o caso prático, deve, através de todos os meios jurisdicionais que lhe são conferidos, aplicar o que for cabível, concedendo, de acordo com o assunto que aqui se trata, a medida provisória, reconhecido o poder tutelar geral do juiz.

A recorribilidade da tutela provisória deve ser realizada por meio do agravo de instrumento, observada a redação do inciso I do artigo 1.015 do Novo CPC: "Art. 1.015. Cabe agravo de instrumento contra as decisões interlocutórias que versarem sobre: I - tutelas provisórias.", sendo o prazo para interposição, de 15 dias. Se não houver recurso de agravo de instrumento por parte do réu, entender-se-á por estabilizada a tutela provisória, tornando seus efeitos consolidados.

Porém, Leonardo Ferres da Silva Ribeiro ${ }^{7}$ diz que pode acontecer o deferimento da tutela provisória na própria sentença, eventualidade que caberá apelação, "sendo certo, porém, que o capítulo relativo ao deferimento desta medida não estará sujeito ao efeito suspensivo, mercê da regra prevista no artigo 1.012, V", que segue: Art. 1.012. "A apelação terá efeito suspensivo. $\S 1^{\circ}$ Além de outras hipóteses previstas em lei, começa a produzir efeitos imediatamente após a sua publicação a sentença que: V - confirma, concede ou revoga tutela provisória;"

Uma outra regra comum às tutelas provisórias é a necessidade de requerimento do interessado para a concessão da tutela provisória. Estabelece o caput do artigo 299 do CPC/73 que "A tutela provisória será requerida ao juízo da causa e, quando antecedente, ao juízo competente para conhecer do pedido principal.”.

Ao mencionar esse tipo de preceito, parece tratar-se de um item óbvio, afinal, o litigante deve formalizar seus interesses, intenções e pedidos no ato da postulação. Mas o ponto que se encontra controverso aqui, é o fato de ser vedada a concessão de tutela provisória ex officio. Fredie Didier8 cita sobre esse aspecto, a regra da congruência, amparada pelo $\mathrm{CPC} / 15$ nos seguintes artigos:

\footnotetext{
${ }^{7}$ RIBEIRO, Leonardo Ferres da Silva. Tutela Provisória: tutela de urgência e tutela da evidência - do CPC/73 ao CPC/2015. São Paulo: Editora Revista dos Tribunais, 2015. Coleção Liebman. P.234

${ }^{8}$ DIDIER JÚNIOR, Fredie; OLIVEIRA, Rafael Alexandria; BRAGA, Paula Sarno. Curso de Direito Processual Civil: teoria da prova, direito probatório, ações probatórias, decisão, precedente, coisa julgada e antecipação dos efeitos da tutela. 10 ${ }^{\mathrm{a}}$ Edição. Vol 2. Salvador: Ed. Jus Podivm. 2015. p. 593.
} 
Art. $2^{\circ} \mathrm{O}$ processo começa por iniciativa da parte e se desenvolve por impulso oficial, salvo as exceções previstas em lei.

Art. 141. O juiz decidirá o mérito nos limites propostos pelas partes, sendo-lhe vedado conhecer de questões não suscitadas a cujo respeito a lei exige iniciativa da parte.

Art. 492. É vedado ao juiz proferir decisão de natureza diversa da pedida, bem como condenar a parte em quantidade superior ou em objeto diverso do que lhe foi demandado.

Parágrafo único. A decisão deve ser certa, ainda que resolva relação jurídica condicional.

"Princípio da congruência ou adstrição refere-se à necessidade do magistrado decidir a lide dentro dos limites objetivados pelas partes, não podendo proferir sentença de forma extra, ultra ou infra petita". No entanto, Fredie Didier ${ }^{9}$ ainda ressalva que é possível a concessão de tutela provisória ex officio somente nas hipóteses expressamente previstas em lei, como é o exemplo da outorga de alimentos, conjecturado pelo artigo $4^{\circ}$ da Lei ${ }^{\circ} 5.478$, de 25 de julho de 1968, que dispõe sobre ação de alimentos:

Art. $4^{\circ}$ As despachar o pedido, o juiz fixará desde logo alimentos provisórios a serem pagos pelo devedor, salvo se o credor expressamente declarar que deles não necessita.

Parágrafo único. Se se tratar de alimentos provisórios pedidos pelo cônjuge, casado pelo regime da comunhão universal de bens, o juiz determinará igualmente que seja entregue ao credor, mensalmente, parte da renda líquida dos bens comuns, administrados pelo devedor.

${ }^{9}$ DIDIER JÚNIOR, Fredie; OLIVEIRA, Rafael Alexandria; BRAGA, Paula Sarno. Curso de Direito Processual Civil: teoria da prova, direito probatório, ações probatórias, decisão, precedente, coisa julgada e antecipação dos efeitos da tutela. 10a Edição. Vol 2. Salvador: Ed. Jus Podivm. 2015. p. 593. 
Excluindo tais eventualidades legais, fica o juiz desautorizado de conceder de ofício a tutela provisória, tendo em vista as regras do "cumprimento provisório de sentença", a efetuação da tutela provisória ocorre sob responsabilidade objetiva do beneficiário da tutela, que segundo Dinamarco ${ }^{10}$ é inato das medidas proporcionadas contra o tempo não se inquietarem pela harmonização da vontade do direito material, determinando ao beneficiário a responsabilidade pelas irregularidades e danos causados, seguindo o princípio do ubi commoda ibi incommoda, que nada mais significa dizer: se o interessado executar medida liminar, deve sujeitar-se a sustentar o risco de ressarcir o dano ou prejuízo eventualmente causado.

\subsection{TUTELA PROVISÓRIA DE URGÊNCIA}

Essa espécie de tutela possui os seguintes pressupostos genéricos: da demonstração da probabilidade do direito, traduzida de maneira conotativa pelo princípio do fumus boni iuris, juntamente com a demonstração do perigo de dano irreparável ou de difícil reparação, também ancorada ao princípio do periculum in mora.

Ao ser apresentado o requisito da probabilidade do direito no processo, o magistrado deverá investigar se existem elementos que destaquem e salientem a veracidade do acontecimento exposto e descrito, e quais as chances de sucesso do demandante quanto àquele pedido.

A concessão de uma tutela provisória de urgência depende também do perigo da demora, pressuposto geral já citado anteriormente. Assim, o litigante deve apontar elementos que evidenciem a ameaça trazida pela demora na concessão da prestação jurisdicional, mostrando a possibilidade de dano irreparável ou de difícil reparação frente à lentidão natural do curso do processo de conhecimento, ou ainda de acordo com o artigo 300 do Novo CPC, caput, "perigo de dano ou o risco ao resultado útil do processo.". Dano irreparável é aquele cujos resultados e repercussão sejam irreversíveis. Dano de difícil reparação é aquele que provavelmente não será indenizado, reembolsado ou suprido.

${ }^{10}$ DINAMARCO, Cândido Rangel. A instrumentalidade do processo. $14^{\mathrm{a}}$ ed. Editora Malheiros, 2009. p. 58. 


\subsubsection{Tutela Provisória de Urgência Cautelar}

Também chamada de tutela conservativa, a modalidade cautelar de tutela provisória de urgência sofreu consideráveis mudanças em face de como era disciplinada pelo Código de Processo Civil de 1973.

O CPC/73 trazia o seu Livro III exclusivamente para tratar do Processo Cautelar, de modo que, segundo Leonardo Ferres da Silva Ribeiro $^{11}$, em decorrência do destaque processual que recebia, foi alçado no mesmo patamar dos processos de conhecimento e de execução, dando origem a um tertium genus, um terceiro gênero de processo, que continha, no seu procedimento, as funções do processo de conhecimento e de execução.

Porém, essa colocação trazida pelo uso e costume jurídico desrespeita o critério homogêneo de classificação, fazendo com que o direito processual ganhe maior ênfase, maior importância perante o direito material, já que o que realmente possui importância é a tutela jurisdicional almejada.

Como base para se perceber o fato de o processo cautelar ter tomado dimensão individualizada no antigo código, tem-se o fato de ser peticionado e processado em uma ação distinta do processo principal, e sendo tratado com autonomia, totalizando-se dois processos.

O Novo CPC, ao compilar toda modalidade antecipatória de tutela em seu Livro V, sob o título de "Da Tutela Provisória", extinguiu a autonomia do processo cautelar, tendo ainda excluído do ordenamento jurídico a existência das quinze seções que tratavam das cautelares nominadas ou cautelares típicas, deixando que o poder tutelar geral do juiz resolva os casos que não estão expressos em lei.

A tutela provisória de urgência cautelar possui finalidade protetiva. Deve garantir o correto funcionamento da jurisdição, já que não possui cunho satisfativo, pois sua função é possibilitar futura satisfação através de atual proteção do direito material, até que o processo alcance o julgamento de mérito do caso.

Nota-se aqui, que o conceito de tutela cautelar, do Código de Processo de Civil de 1973 para o Código de Processo Civil de 2015, per-

\footnotetext{
${ }^{11}$ RIBEIRO, Leonardo Ferres da Silva. Tutela Provisória: tutela de urgência e tutela da evidência - do CPC/73 ao CPC/2015. São Paulo: Editora Revista dos Tribunais, 2015. Coleção Liebman. p. 96.
} 
manece o mesmo: possui o desígnio de proteger e assegurar um direito. Não se antecipa o resultado, apenas protege-o.

\subsubsection{Tutela Provisória de Urgência Antecipada}

Ao realizar o pedido de uma tutela provisória cautelar antecipada, a parte pretende encerrar ou evitar o perigo de dano que esteja iminente, garantindo assim, a imediata concretização dos benefícios do direito material; e para isso, terá de se valer do procedimento próprio que a tutela satisfativa recebeu, pois se a urgência que atormenta a parte estiver ocorrendo contemporaneamente ao momento da propositura da ação principal, a parte deverá confeccionar sua petição inicial delimitando apenas o pedido da tutela antecipada, ou seja, o pedido será realizado no momento antecedente ao processo principal, na qual deverá apresentar a satisfação dos requisitos que englobam o fumus boni iuris, mas não deixando de demonstrar também o direito que pretende satisfazer e ainda o perigo na demora da prestação da tutela antecipada. Protocolada essa peça, a parte terá 15 dias para aditar a inicial, de modo a ratificar o seu pedido final.

A eficácia do novo sistema permite que seja realizada a cognição sumária, acompanhada de uma satisfação precipitada ao tempo do processo exauriente, permitindo à parte receber os efeitos da tutela em tempo hábil perante o perigo de dano irreparável ou de difícil reparação em que se encontre.

\subsection{TUTELA PROVISÓRIA DE EVIDÊNCIA}

A tutela provisória de evidência, ao contrário da tutela de urgência, não possui fundamento no fato da circunstância da qual desenvolve-se o perigo de dano, mas baseia-se no reconhecimento, através da comprovação e constatação, de direito material do litigante.

$O$ fundamento que veio trazer à luz da legislação a tutela de evidência é o fato de que a duração do processo, que demanda muito tempo, não deve resultar em um estrago para quem já comprovou ser possuinte do direito dentro do antagonismo processual, que ao final do procedimento exauriente, seria o real detentor do provimento resultado de decisão definitiva. 
Porém, uma decisão a favor daquele que é possessor do direito material não significa o fim do processo, tratando-se de um julgamento antecipado da lide, a tutela de evidência, depois de proferida conferirá ao processo a sua continuidade, permitindo à parte opositora apresentar o seu contraditório e instrução probatória.

A tutela de evidência, diferentemente das demais tutelas provisórias, não pode ser requerida em caráter antecedente, pois a natureza da assistência a que presta, tem como pressuposto a existência de uma ação principal já ajuizada.

\section{CONSIDERAÇÕES FINAIS}

A tutela provisória é coluna no processo civil que visa reduzir os efeitos do tempo do processo, pois expor uma situação ao tempo que leva o processo de conhecimento para composição da decisão de mérito, pode trazer sérios riscos, causar prejuízo ou danos irreparáveis, pois poderia ter sido acolhida em momento jurídico anterior, não permitindo que nenhum dano fosse causado.

Aprovado o Novo Código de Processo Civil, que passou a vigorar em 2015, muitas mudanças ocorreram, que a nosso ver, foram para melhorar, simplificar, tornar prático e efetivo o processo que visa à obtenção de uma tutela provisória.

A tutela provisória, objeto da ação definitiva pode ser antecipada ou cautelar. A tutela antecipada tem o objetivo de efetivar e certificar o direito já existente, e a tutela cautelar apenas protege o direito, deixandoo assegurado durante o processo e sobre o tempo a que ficará exposto.

$\mathrm{O} \mathrm{CPC} / 15$, ao compilar as cautelares e as antecipadas em seu Livro V, sob o título de "DA TUTELA PROVISÓRIA", trouxe a unificação dessas medidas para que se pudesse simplificar o entendimento e aumentar seu campo de aplicação. Ou seja, a tutela antecipada que era tratada no artigo 273 do CPC/73 e a tutela cautelar que era disciplinada pelo Livro III, agora fazem parte de um mesmo rol que vem proteger o direito de maneira a oferecer um respaldo diferenciado.

Então, o CPC/15 separou a tutela provisória em duas ramificações: a tutela provisória de urgência, que também foi subdividida em cautelar e antecipada; e a tutela provisória de evidência. Ao unificar o sistema provisório de provimentos jurisdicionais, o Novo CPC excluiu do 
ordenamento as cautelares típicas, que elencavam os requisitos necessários a serem preenchidos para fornecimento certeiro de uma tutela cautelar, permitindo à parte se encarregar de ocupar os pressupostos genéricos, de modo que o juízo, com seu poder geral de cautela, possa valorar o caso conforme achar necessário, e conceder ou não a tutela provisória.

Porém, não ficam excluídos os conceitos que o $\mathrm{CPC} / 73$ trazia acerca dos conceitos de arresto, sequestro, arrolamento de bens e registro de protesto contra alienação de bem, que são os institutos trazidos de maneira específica pelo Novo Código, deixando clara a intenção do legislador de se fazer a utilização subsidiária e doutrinária destas medidas que foram remodeladas.

Essas conclusões são pautadas no otimismo de melhoria que este Novo Código de Processo Civil promete, afinal, se foi necessário confeccionar um novo Diploma ao invés de reformar o já existente, é sinal de que o CPC/73 já não era capaz de acompanhar as necessidades sociais e processuais da contemporaneidade. Possui ainda, no assunto em pauta a respeito da tutela provisória, uma organização topográfica mais organizada, unificada, e ao mesmo tempo não se deixam misturar os diferentes conceitos que cada instituto recebe, mas também sem permitir que o direito material seja afetado por erros formais ou processuais através da fungibilidade, que se faz presente.

E por fim, os objetivos deste trabalho se fizeram cumpridos, permitindo ao leitor ter acesso aos conceitos necessários, juntamente com a função constitucional da tutela provisória e suas ramificações trazidas pelo Novo Código, acompanhada do detalhamento das principais modificações que ocorreram.

\section{REFERÊNCIAS BIBLIOGRÁFICAS}

AMARAL, Guilherme Rizzo. Comentários às alterações do novo CPC. São Paulo: Editora Revista dos Tribunais, 2015.

CARVALHO, Newton Teixeira. Da tutela provisória. In.: domtotal.com. Belo Horizonte-MG, 2015. Disponível em: $<$ http://www.domtotal.com/colunas/detalhes.php?artId=5454 $>$. Acesso em 06 mar 2016.

DIDIER JÚNIOR, Fredie; OLIVEIRA, Rafael Alexandria; BRAGA, Paula Sarno. Curso de Direito Processual Civil: teoria da prova, 
direito probatório, ações probatórias, decisão, precedente, coisa julgada e antecipação dos efeitos da tutela. 10 ${ }^{\mathrm{a}}$ Edição. Vol 2. Salvador: Ed. Jus Podivm. 2015.

DINAMARCO, Cândido Rangel. A instrumentalidade do processo. $14^{\mathrm{a}}$ ed. Editora Malheiros, 2009.

DOTTI, Rogéria. Tutela Cautelar e Tutela Antecipada no CPC de 2015: Unificação dos Requisitos e Simplificação do Processo. Paraná, 14 de abril de 2015. Disponível em: <http://www.migalhas.com.br/dePeso/16,MI218846,101048Tutela+Cautelar+e+Tutela+Antecipada+no+CPC+de+2015+ Unificacao+dos>. Acesso em: 05 jan. 2016.

FERREIRA, A. B. H. Aurélio: O dicionário da língua portuguesa. Minidicionário Aurélio. $8^{\text {a }}$ edição. Curitiba: Positivo, 2010.

FREIRE, Alexandre Reis Siqueira; BARROS, Rute de Jesus da Costa. As novas tendências do Código de Processo Civil. São Luis-MA. Disponível em: $<$ http://www.ambitojuridico.com.br/site/?n_link=revista_artigos_leitura\&artigo_i $\mathrm{d}=10960$ \&revista_caderno=21>. Acesso em: 07 jan. 2016.

FUGA, Bruno Augusto Sampaio. BATISTA, Magno Alexandre Silveira. Responsabilidade nas tutelas de urgência. In.: Páginas de Direito - Excelência em Conteúdo Jurídico. Porto Alegre, 2014. Disponível em: <http://www.tex.pro.br/home/artigos/262artigos-abr-2014/6496-responsabilidade-nas-tutelas-deurgencia>. Acesso em: 6 mar 2016.

GAJARDONI, Fernando da Fonseca. DELLORE, Luiz. ROQUE, Andre Vasconcelos. JR., Zulmar Duarte de Oliveira. Teoria Geral do Processo: comentários ao CPC de 2015: parte geral. São Paulo: Forense, 2015.

GOMES, Rede de Ensino Luiz Flávio. O que se entende por Princípio da Congruência ou Adstrição? - Mariana Egídio Lucciola. In.: Jusbrasil. São Paulo, $2010 . \quad$ Disponível em: <http://lfg.jusbrasil.com.br/noticias/1927947/o-que-seentende-por-principio-da-congruencia-ou-adstricao-marianaegidio-lucciola> Acesso em: 06 mar 2016.

GSCHWENDTNER, Loacir. Precisamos de um Novo Código de Processo Civil? São Bento do Sul, nov. 2010. Disponível em: $<$ https://jus.com.br/artigos/17956/precisamos-de-um-novocodigo-de-processo-civil>. Acesso em: 07 jan. 2016. 
MARINONI, Luiz Guilherme. MITIDIERO, Daniel. Código de Processo Civil Comentado Artigo por Artigo. $5^{\text {a }}$ Edição revista e atualizada. 2013.

MARTINS, Rachel Figueiredo Viana. O Princípio da Fungibilidade na Medida Cautelar. 2 mar. 2010. Disponível em: <http://www.direitonet.com.br/artigos/exibir/5605/OPrincipio-da-Fungibilidade-na-Medida-Cautelar>. Acesso em: 11 jan. 2016.

NUNES, Elpídio Donizetti. Novo código de processo civil comentado (Lei 13.105, de 16 de março de 2015): análise comparativa entre o novo CPC e o CPC/73. São Paulo: Atlas, 2015.

ORIONE NETO, Luiz. Tratado das Medidas Cautelares. Teoria Geral do Processo Cautelar. Vol. III. São Paulo. Lejus, 2000, p.198/200. RANGEL, Tauã Lima Verdan. Comentários ao poder geral de cautela no processo civil: anotações introdutórias. In: Âmbito Jurídico, Rio Grande, XVI, n. 116, set 2013. Disponível em: $<$ http://www.ambitojuridico.com.br/site/?n_link=revista_artigos_leitura\&artigo_i $\mathrm{d}=13152 \&$ revista_caderno=21>. Acesso em 06 mar 2016.

RIBEIRO, Leonardo Ferres da Silva. Tutela Provisória: tutela de urgência e tutela da evidência - do CPC/73 ao CPC/2015. São Paulo: Editora Revista dos Tribunais, 2015. Coleção Liebman.

THEODORO JÚNIOR, Humberto. Curso de Direito Processual Civil: processo de execução e cumprimento de sentença. Processo cautelar e tutela de urgência Volume II. 49 ${ }^{\mathrm{a}}$ Edição. Rio de Janeiro: Forense. 2014.

THEODORO JÚNIOR, Humberto. Curso de Direito Processual Civil: Teoria geral do direito processual civil e processo de conhecimento - Vol. I. 55 Edição. Rio de Janeiro: Forense. 2014.

THEODORO JÚNIOR, Humberto. Curso de Direito Processual Civil: Teoria geral do direito processual civil, processo de conhecimento e procedimento comum - Vol. I. 56 $6^{\text {a }}$ Edição rev. atual. e ampl. Rio de Janeiro: Forense. 2015.

TIMBÓ, Bruna. A Fungibilidade entre a Tutela Antecipada e a Medida Cautelar: Mão Dupla. São Paulo, 14 fev. 2005. Disponível em:

<http://www.direitonet.com.br/artigos/exibir/1918/A- 
fungibilidade-entre-a-tutela-antecipada-e-a-medida-cautelarmao-dupla>. Acesso em: 05 jan. 2016. 